\title{
NILAI-NILAI KEARIFAN LOKAL DALAM TRADISI MISALIN DI KECAMATAN CIMARAGAS KABUPATEN CIAMIS
}

\author{
Dewi Ratih \\ Program Studi Pendidikan Sejarah FKIP Universitas Galuh Ciamis \\ Email:ratihdewi231@gmail.com
}

\begin{abstract}
ABSTRAK
Tradisi Misalin merupakan upacara adat yang dilaksanakan secara rutin setiap setahun sekali di Desa Cimaragas menjelang bulan suci Ramadhan. Banyak masyarakat yang mengetahui dan bahkan mengikuti tradisi tersebut, tetapi belum menyadari penuh nilai-nilai kearifan lokal yang terkandung di dalamnya. Oleh karenanya, tulisan ini bertujuan untuk mengetahui pelaksanaan dan nilai-nilai kearifan lokal Tradisi Misalin di Desa Cimaragas. Metode yang digunakan adalah metode historis, yang terdiri dari heuristik, kritik, interpretasi, dan historiografi. Hasil penelitian menunjukkan bahwa Tradisi Misalin memiliki nilai-nilai kearifan lokal, di antaranya nilai religius, gotong royong, seni, sejarah, dan ekonomi.
\end{abstract}

\section{Kata kunci: Tradisi, Misalin, Kearifan Lokal}

\section{ABSTRACT}

Misalin tradition is a traditional ceremony that is held regularly every year in the village of Cimaragas before the holy month of Ramadan. Many people know and even follow these traditions but have not yet fully realized the values of local wisdom contained within them. Therefore, this paper aims to find out the implementation and values of local wisdom of the Misalin Tradition in Cimaragas Village. The method used is the historical method, which consists of heuristics, criticism, interpretation, and historiography. The results of the study indicate that Misalin Tradition has local wisdom values, including religious values, cooperation, art, history, and economy.

\section{Keywords: Tradition, Misalin, Local Wisdom}

\section{PENDAHULUAN}

Manusia merupakan

makhluk Tuhan yang mempunyai kesempurnaan dibanding makhluk yang lainnya, karena memiliki akal dan budi. Akal dan budi inilah yang kemudian memunculkan produkproduk manusia yang disebut sebagai kebudayaan. Salah satu hasil kebudayaan manusia adalah tradisi yang dilaksanakan secara turun temurun. Hal tersebut tentunya tidak serta merta begitu saja diwariskan dari satu generasi ke generasi selanjutnya, karena ada 
nilai-nilai yang akan disampaikan dalam tradisi tersebut.

Apabila kita memahami kembali mengenai makna kebudayaan dapatlah dikatakan bahwa kebudayaan merupakan cermin masyarakat dan tidak bisa dilepaskan dari perilaku masyarakat pendukungnya. Sikap dan konfigurasi yang ada pada perilaku masyarakat tertentu dapat dipahami dengan cara memahami kearifan yang ada pada daerah tertentu. Oleh karenanya kita harus mampu memahami kebudayaan yang berasal dari berbagai masyarakat pendukungnya.

Jawa Barat terutama daerah Ciamis merupakan daerah yang mempunyai keanekaragaman budaya baik benda (tangible) ataupun tak benda (intangible). Warisan budaya tersebut perlu dilestarikan dan dikembangkan agar tetap menjadi kekayaan yang utuh bagi kebudayaan Jawa Barat khususnya Ciamis. Salah satu tempat di Kabupaten Ciamis yang mempunyai warisan budaya tak benda adalah Cimaragas yang memiliki Tradisi Misalin. Tradisi ini dilaksanakan menjelang bulan suci Ramadhan. Oleh karenanya, Tradisi Misalin ini juga dikenal dengan tradisi Mapag Ramadhan. Tradisi ini dilaksanakan secara turun temurun oleh masyarakat sekitar karena selain merupakan kekayaan budaya tak benda, juga memiliki nilai-nilai kearifan lokal, yang penting untuk diketahui dan diterapkan dalam kehidupan sehari-hari masyarakat secara umum.

Kearifan lokal memiliki peran dan fungsi yang penting, hal ini ditegaskan oleh Sartini (2006) bahwa peran dan fungsi kearifan lokal adalah: (1) untuk konservasi dan pelestarian sumber daya alam, (2) pengembangan sumber daya manusia, (3) pengembangan kebudayaan dan ilmu pengetahuan, (4) sebagai sumber petuah/kepercayaan/sastra dan pantangan, (5) sebagai sarana membentuk dan membangun integrasi komunal, (6) sebagai landasan etika dan moral, dan (7) fungsi politik (Basyari, 2014:48). 
Pendapat Sartini tersebut menunjukkan pentingnya kearifan lokal dari Tradisi Misalin ini.

Berdasarkan uraian di atas, maka disusunlah rumusan masalah seperti di bawah ini:

1. Bagaimana pelaksanaan Tradisi Misalin?

2. Apa nilai-nilai kearifan lokal yang terkandung dalam tradisi Misalin?

\section{KAJIAN PUSTAKA}

Menurut Fraenkel (1977), nilai (value) merupakan wujud dari aspek afektif (affective domain) serta berada dalam diri seseorang, dan secara utuh dan bulat merupakan suatu sistem, di mana bermacam nilai (nilai keagamaan, sosial budaya, ekonomi, hukum, estetis, etik, dan lain-lain) berpadu jalin-menjalin serta saling mempengaruhi satu sama lain secara kuat sebagai suatu kesatuan yang utuh. Sistem nilai ini sangat dominan menentukan perilaku dan kepribadian seseorang (Yunus, 2014:17).

Kearifan lokal (lokal wisdom) adalah produk budaya masa lalu yang dipercaya dapat memberi kontribusi terhadap terciptanya kehidupan yang damai dan tenteram. Sebagai produk kearifan lokal. Kearifan (wisdom) secara etimologi berarti kemampuan seseorang dalam menggunakan akal pikirannya untuk menyikapi sesuatu kejadian, obyek atau situasi. Sedangkan lokal menunjukkan ruang interaksi di mana peristiwa atau situasi tersebut terjadi. Kearifan lokal merupakan perilaku positif manusia dalam berhubungan dengan alam dan lingkungan sekitarnya, yang dapat bersumber dari nilai agama, adat istiadat, petuah nenek moyang atau budaya setempat, yang terbangun secara alamiah dalam suatu komunitas masyarakat untuk beradaptasi dengan lingkungan di sekitarnya. Perilaku yang bersifat umum dan berlaku di masyarakat secara meluas, turun temurun, akan berkembang menjadi nilai-nilai yang dipegang teguh, yang disebut sebagai kebudayaan (budaya) (Wikantiyoso dan Tutuko, 2009:07). 
Tradisi dalam bahasa latin traditio, yang berarti diteruskan atau kebiasaan. Dalam Tesaurus Bahasa Indonesia, tradisi berarti adat kebiasaan turun-temurun (dari nenek moyang) yang masih dijalankan oleh masyarakat (Sugono (red)., 2008: 1438). Pengertian tradisi oleh C.A. Van Peursen diterjemahkan sebagai proses pewarisan atau penerusan norma-norma, adat istiadat, kaidah-kaidah, harta-harta. Pada dasarnya tradisi dapat diubah, diangkat, ditolak, dan dipadukan dengan aneka ragam perbuatan manusia. Tradisi tersebut bahkan bukan hal yang tidak dapat diubah, melainkan dapat dipadukan dengan aneka ragam perbuatan manusia dan diangkat secara keseluruhan (Peursen, 1988: 11). Tradisi dalam pengertian yang paling sederhana adalah sesuatu yang telah dilakukan sejak lama dan menjadi bagian dari kehidupan suatu kelompok masyarakat, biasanya dari suatu negara, kebudayaan, waktu, atau agama yang sama. Hal yang paling mendasar dari tradisi adalah adanya informasi yang diteruskan dari generasi ke generasi baik tertulis maupun (sering kali) lisan, karena tanpa adanya ini, suatu tradisi dapat punah (Nasution dkk, 2015:82). Dapat disimpulkan bahwa, tradisi merupakan suatu pewarisan kebiasaan secara turuntemurun yang diwariskan dari satu generasi ke generasi selanjutnya yang dapat berupa suatu upacara adat ataupun kegiatan-kegiatan lainnya.

\section{METODE PENELITIAN}

Metode yang digunakan dalam penelitian ini adalah Metode Sejarah. Metode sejarah merupakan suatu prosedur, teknik, atau cara melakukan penyelidikan yang sistematis sesuai fakta-fakta yang diterima sebagai sesuatu yang benar. Sementara itu, menurut (Gottschalk, 1975:32) yang dimaksudkan dengan metode sejarah adalah proses menguji dan menganalisis secara kritis rekaman dan peninggalan masa lampau.

Ada empat langkah yang harus dilakukan saat menggunakan 
metode Hitoris, yaitu heuristik, kritik, interpretasi dan historiografi (Herlina, 2008:15). Heuristik yaitu mengumpulkan sumber-sumber sejarah. Kritik adalah tahap meneliti sumber, informasi, jejak tersebut secara kritis, menilai sumber dan memilih sumber sejarah. Interpretasi merupakan tahap menafsirkan fakta-fakta sejarah yang sudah didapat oleh penulis. Historiografi merupakan penulisan sejarah, kegiatan menyampaikan hasil-hasil rekonstruksi imaginatif masa lampau itu sesuai dengan jejakjejaknya, historiografi merupakan tahapan akhir dalam langkahlangkah penelitian sejarah.

\section{PEMBAHASAN}

\section{Pelaksanaan Tradisi Misalin}

$$
\text { Menjelang bulan suci }
$$

Ramadhan banyak tradisi-tradisi adat yang dilakukan oleh masyarakat yang dapat kita jumpai di wilayah Kabupaten Ciamis. Tradisi-tradisi tersebut dilaksanakan di situs-situs bersejarah yang memiliki nilai historis yang tinggi. Tradisi-tradisi tersebut di antaranya seperti Misalin, Merlawuh, Nyepuh dan tradisi-tradisi lain yang dilakukan. Tidak terkecuali yang selalu diadakan oleh masyarakat adat Salawe, yaitu tradisi Misalin. Tradisi ini dilakukan di area Situs Bojong Salawe.

Situs Petilasan Sang Hyang Cipta Permana Prabu di Galuh atau yang lebih dikenal dengan Situs Bojong Salawe secara administratif terletak di Dusun Tunggarahayu Rt 24 Rw 09 Desa Cimaragas Kecamatan Cimaragas Kabupaten Ciamis. Situs ini secara astronomi berada pada koordinat $07^{\circ} 21^{\prime} 37,4^{\prime \prime}$ LS dan $108^{\circ} 27^{\prime} 07,5^{\prime \prime}$ BT dengan ketinggian $82 \mathrm{mdpl}$. Lahan situs ini berada di dekat sungai Citanduy tepatnya di sebelah Utara situs dan tempatnya rimbun oleh hutan bambu (Mujamil dan Widiyanti, 2014: 273).

Misalin secara harfiah berarti melakukan pergantian menuju kesejahteraan hidup lahir dan batin. Misalin terdiri dari dua kata yaitu mi dan salin. Mi berarti suatu kegiatan yang ada perubahan 
sedangkan salin berarti ganti. Misalin berarti suatu kegiatan berganti dari yang buruk ke arah yang baik. Kegiatan Misalin ini juga merupakan kegiatan membersihkan lingkungan, juga sebagai pembersihan diri untuk menyambut bulan Ramadhan. Kegiatan ini juga sebagai ajang silaturahmi dan saling memaafkan antar manusia dengan manusia sebelum menginjak bulan

\section{Ramadhan.}

Tradisi tahunan ini telah dilakukan masyarakat secara turun-temurun di sekitar situs Petilasan Sang Hyang Cipta Permana Prabu di Galuh yang berada di Dusun Tunggarahayu, Desa Cimaragas, Kecamatan Cimaragas, Kabupaten Ciamis. Pada tradisi ini, masyarakat bergotong royong membersihkan makam leluhur, sekaligus berdoa di tempat tersebut, untuk menyucikan diri (Dinas Pariwisata, $\mathrm{tt}: 24$ ).

Selain memiliki arti secara harfiah, tradisi Misalin memiliki makna yang tersirat yakni memagari diri dari berbagai hawa nafsu jahat saat memasuki bulan Ramadhan, juga memiliki makna yaitu beralih dari perilaku yang buruk ke perilaku yang baik. Dan ketika memasuki bulan Ramadhan hati kita sudah bersih ataupun suci. Tradisi menjelang bulan Ramadhan tersebut selain diikuti oleh masyarakat Cimaragas, tetapi juga diikuti oleh masyarakat dari wilayah lain. Dan setiap tahunnya selalu dihadiri oleh para sesepuh dari berbagai daerah (Hadiwijaya, wawancara tanggal 5 Mei 2018).

Sebelum pelaksanaan tradisi Misalin diadakan, masyarakat Salawe terlebih dahulu mempersiapkan segala sesuatu hal untuk pelaksanaan tradisi Misalin. Dalam hal peralatan mulai dipersiapkan seperti bambu, janur (daun kelapa yang masih muda), damar (sebagai alat penerangan tradisional untuk ritual Ngadamar), pontrang (wadah yang terbuat dari daun kelapa untuk dijadikan wadah makanan). Tenda yang digunakan, tiangnya dari

bambu atapnya terbuat dari daun dahon (daun yang hampir 
mirip dengan daun kelapa) yang sudah kering dan untuk tempat duduknya dibuat secara lesehan, Kemudian untuk pentas seni budayanya, kesenian yang ditampilkan adalah seni Bangbaraan, Pontrangan, Pencak Silat, dan Seni Rudat (Tirtawijaya, Wawancara tanggal 2 Juli 2018).

Sebelum dilaksanakan acara inti Tradisi Misalin, masyarakat terlebih dahulu melaksanakan ritual Ngadamar yang dilaksanakan malam hari sekitar pukul 20.00 WIB. Setelah semua tamu undangan telah hadir, acara mulai dilaksanakan dari alun-alun menuju ke lokasi situs Bojong Salawe, setelah sampai di lokasi situs ada pembacaan rajah, kemudian tawasulan (memanjatkan do'a-do'a), tepatnya di area Pamidangan. Tawasulan ini juga sebagai bentuk do'a agar esok hari diberikan kelancaran. Selain itu juga dibacakan pula rajah. Rajah dibacakan oleh Bapak Aip Saripudin. Maksud pembacaan rajah tersebut adalah sebagai bentuk doa-doa agar acara esok hari diberi kelancaran. Rajah berarti doa. Isi dari rajah tersebut beserta terjemahannya adalah sebagai berikut:

Amit ampun nya paralun Ka gusti nu Maha Agung Ka Nabi anu lihunung Muhammad anu jinunjung Rohmat syafaat kasuhun Simkuring neda papayung

Kaluhur neda papayung Papayung nu Maha Agung Ka handap neda pangraksa Pangraksa maha kawasa Kaler kuln kidul wetan Mugi diaping dijaring

Ti lihur ti karuhun

Ti buyut ti nini aki Nu nurutkeun kabudayaan Degung pantun tembang kawih Ieu abdi sadayana

Seja ngaraksa mupusti $2 x$

Amit ka nu mangku lembur Ka nu nyungsi di nu sepi $\mathrm{Nu}$ keur genah tumaninah Bisi kausik keur calik Kalangkah kaliliwatan $2 x$ Neda Agung nya hak sami $2 x$ Amit ngahudang wayangkeun

Terjemahan:

Mohon ijin dan ampunan Kepada Tuhan yang maha agung Kepada Nabi yang teristimewa Muhammad SAW yang dijunjung Rahmat Syafaat Hamba memohon perlindungan 
Kepada yang di atas memohon perlindungan

Perlindungan yang Maha Agung

Kepada yang di bawah memohon bimbingan

Bimbingan yang maha kuasa

Utara Barat Selatan Timur

Semoga dituntun, dilindungi

Dari atas dari nenek moyang Dari buyut dari kakek nenek

Yang sesuai kebudayaan

Lantunan pantun dan tembang kawih

Dan kami semua

Untuk mengintrospeksi diri

Mohon ijin kepada yang

memelihara kampung

Kepada yang diam dalam sepi

Yang sedang berdiam dalam

ketenangan

Takut terusik saat duduk

Terlangkahi, terlewati $2 \mathrm{X}$

Mohon keadilan dari yang maha

Agung

Mohon ijin membangunkan

Setelah tawasulan dan juga pembacaan Rajah berakhir, kemudian masyarakat melakukan iring-iringan menuju ke pinggir sungai Citanduy yang disebut Parung Ayu. Di sana diadakan acara menuangkan air yang berasal dari 7 sumber mata air keramat yang dimasukkan ke sebuah wadah besar yang esok hari juga akan digunakan untuk acara kuramasan.
Air tersebut berasal dari Karangkamulyan, Jambansari, Kawali, Singaperbangsa 3, Mata Air Nusantara, Pancawarna Salawe, dan Lakbok. Air yang berada dalam lodong tersebut dituangkan ke dalam sebuah wadah yang disebut Gentong Kencana.

Setelah itu, di Parung Ayu juga ada sambutan dari perwakilan Direktorat Jenderal Kepercayaan Kepada Tuhan Yang Maha Esa dan Tradisi dilanjutkan sambutan dari perwakilan Dinas Pariwisata kabupaten Ciamis. Kemudian Abah Latif (sebagai tokoh Situs Bojong Salawe) membacakan Pasaduan. Pasaduan berarti meminta ijin. Pembacaan Pasaduan ini bermaksud untuk meminta ijin untuk kelancaran acara tradisi Misalin yang akan dilaksanakan esok hari. Setelah selesai acara di Parung Ayu, semua iring-iringan kemudian kembali ke alun-alun, menandakan berakhirnya acara Ngadamar.

Pada esok harinya sekitar pukul 07.00 WIB masyarakat sudah berkumpul, dan kemudian 
mempersiapkan untuk acara iringiringan dari pintu masuk menuju Lembur Salawe/situs Bojong Salawe, dari iringan-iringan tersebut terdapat para tamu undangan, ibu-ibu membawa boboko yang di dalamnya terdapat pontrang yang sudah diisi makanan.

Sebelum ke acara tawasulan, diadakan juga acara kuramasan untuk anak-anak kecil atau pinggir sungai Citanduy (Parung Ayu). Kuramasan ini adalah upacara membersihkan diri untuk menyambut Ramadhan. Selain dari masyarakat Salawe, bahkan masyarakat lain pun biasanya melakukan kuramas sehari sebelum bulan Ramadhan atau lebih identik dengan adus. Supaya ketika menginjak bulan Ramadhan sudah kembali suci.

Setelah selesai kuramasan barulah acara tawasulan dimulai. Tawasulan dilaksanakan di dalam situs Bojong Salawe Cimaragas. Acara tawasulan ini dilaksanakan untuk mendoakan arwah nenek moyang yang telah meninggal.
Terutama nenek moyang dari masyarakat adat Salawe, dan juga untuk semua umat manusia yang telah meninggal dunia. Setelah acara tawasulan selesai, kemudian masyarakat yang ada di situs tersebut melakukan musopahah atau bersalam-salaman sebagai tanda saling meminta maaf sebelum menginjak bulan Ramadhan. Dan ketika menginjak bulan Ramadhan hati sudah kembali suci dan siap melaksanakan puasa dalam keadaan hati yang bersih.

Setelah selesai tawasulan, masyarakat kemudian meninggalkan Situs Bojong Salawe dan mulai bergerak menuju ke alun-alun. Dan ketika sampai di alun-alun ada upacara adat mapag tamu. Upacara adat mapag tamu diadakan untuk menyambut tamutamu yang datang dengan memakaikan kain iket khas Ciamis. Acara dimulai dengan pembukaan ayat-ayat suci Alqur'an dilanjut dengan sambutan-sambutan. Setelah itu, sebagai acara penutup, pagelaran seni dipentaskan 
bersamaan dengan acara menikmati hidangan yang tersedia dalam pontrangan (wadah makanan yang terbuat dari daun kelapa).

2. Nilai-Nilai Kearifan Lokal Tradisi Misalin

a. Nilai Religi

Hakikatnya, tradisi ini adalah memohon keselamatan kepada Allah SWT (Tuhan Yang Maha Kuasa). Tradisi Misalin merupakan ungkapan syukur kepada Tuhan Yang Maha Esa. Selain ungkapan syukur, Tradisi Misalin juga dipenuhi oleh kegiatan berdoa kepada Tuhan Yang Maha Esa agar dapat mencapai keselamatan hidup. Do'a-do'a dipanjatkan dalam bahasa Sunda dan ayat-ayat Al-Qur'an. Dengan harapan supaya masyarakat dapat menjalankan ibadah puasa dengan lancar, sehat, selamat, terhindar dari segala gangguan yang dapat membatalkan puasa. Semua ini sebenarnya menggambarkan budi pekerti Sunda yang selalu memproses diri melalui penyucian diri untuk memohon kepada yang
Maha Kuasa. Wujud pengabdian dan ketaatan tersebut ditunjukkan oleh masyarakat dalam Tradisi Misalin melalui pembacaan ayatayat suci Al-Qur'an dan do'a-do'a.

b. Nilai Gotong Royong

Prosesi Tradisi Misalin tidak dapat berjalan lancar jika masyarakat hanya bekerja sendirisendiri. Mereka harus dapat bertanggung jawab, bermusyawarah, menjaga kerukunan dan gotong-royong, serta melestarikan alam. Dengan begitu, tumbuh solidaritas di antara mereka sehingga tidak akan menemukan masalah yang berarti saat mempersiapkan acara Tradisi Misalin sebagai salah satu upaya penghormatan terhadap leluhur. Rasa sosial, kesatuan, dan persatuan sangat diperlukan agar Tradisi Misalin tetap langgeng. Berbagai generasi, kakek dan nenek, ayah dan ibu, hingga anakanak turut bekerja keras demi kelangsungan tradisi yang mereka miliki. 
c. Nilai Seni

Pagelaran seni $\begin{array}{r}\text { yang } \\ \text { ditampilkan dalam acara }\end{array}$
Misalin terdiri dari
pertunjukkan, di

Rudat, Karinding, Pontrangan, dan

Bajidor. Pertunjukkan seni ini oleh masyarakat dijadikan sebagai sarana hiburan. Hal ini bertujuan untuk memberikan pengalaman estetis pada penonton. Biasanya penonton melihat kesenian ini bertujuan untuk melepas lelah, menghilangkan stres, dan bersantai disela-sela kesibukan bekerja. Selain sebagai sarana hiburan, seni juga berfungsi untuk pemanggilan kekuatan gaib; (2) penjemput roh-roh untuk hadir di tempat pemujaan; (3) memanggil roh-roh baik untuk mengusir rohroh jahat; (4) peringatan pada nenek moyang dengan menirukan kegagahan maupun kesigapannya; (5) pelengkap upacara sehubungan dengan peringatan tingkat-tingkat hidup seseorang; (6) pelengkap upacara sehubungan dengan saatsaat tertentu dalam perputaran waktu; (7) pewujudan daripada dorongan untuk mengungkapkan keindahan semata (Nalurita, dkk. t.t.: 3).

d. Nilai Sejarah

Tradisi Misalin ini tidak lepas dari nilai sejarah karena dalam perjalanan kesenian tersebut berlangsung secara turun temurun dari generasi ke generasi selanjutnya. Tradisi Misalin hidup dalam pikiran masyarakat dan dianggap bernilai, berharga, dan penting dalam hidup mereka. Nilai budaya menuntun sikap dan memberi arahan pada hidup masyarakat layaknya leluhur mereka, menghormati tradisi yang ada agar mereka mendapat keselamatan dan kesejahteraan dalam hidup. Perilaku yang berdasarkan pada budaya dirasa perlu di zaman modern seperti sekarang. Hal ini bertujuan agar generasi muda bangsa Indonesia tidak lupa akan jati dirinya. Melalui pelestarian warisan budaya lokal, maka generasi yang akan datang dapat belajar dari warisan-warisan itu dan menghargainya 
sebagaimana yang dilakukan pendahulunya. Seperti fungsi sejarah secara ekstrinsik dapat dikemukakan salah satunya adalah untuk pendidikan (edukasi), baik itu pendidikan moral, penalaran, perubahan, keindahan, rekreasi, dan lainnya.

e. Nilai Ekonomi

Tradisi Misalin, memiliki nilai ekonomi karena pelaksanaannya menjadi aset pariwisata bagi Kabupaten Ciamis. Tidak hanya pemerintah saja yang merasakan dampak finansial positif, tetapi juga masyarakat itu sendiri. Dengan demikian, dapat diketahui bahwa pelaksanaan Tradisi ini mengandung nilai ekonomi. Nilai ini dipercaya dan dijadikan mata pencaharian hidup bagi masyarakat sekitar agar mereka mendapatkan rezeki yang berlimpah. Masyarakat di sekitar situs umumnya menjadi pedagang makanan dan minuman. Hal ini dilakukan masyarakat demi memenuhi kebutuhan dan meningkatkan pendapatan mereka. Tradisi Misalin yang merupakan acara tahunan dapat menjadi aset Pemerintah Daerah Kabupaten Ciamis di sektor pariwisata.

\section{SIMPULAN}

Tradisi Misalin merupakan tradisi yang selalu dilaksanakan setiap tahunnya menjelang bulan Ramadhan. Sebelum kepada acara tradisi Misalin, masyarakat salawe terlebih dahulu melaksanakan Ngadamar pada malam harinya. Tradisi Misalin diawali dengan masyarakat berjalan kaki beriringan menuju lokasi situs. Kemudian sebelum menginjak ke acara inti dari tradisi Misalin yaitu Tawasulan, maka terlebih dahulu diadakan Kuramasan di Parung Ayu yang berada di pinggir sungai Citanduy. Setelah selesai Kuramasan, dilanjutkan dengan Tawasulan untuk mendoakan para leluhur, khususnya leluhur Situs Bojong Salawe. Setelah selesai Tawasulan, dilanjutkan dengan Musopahah sebagai akhir dari acara inti tradisi Misalin. Selain acara inti dari tradisi Misalin, tradisi Misalin pada tahun ini juga ditambahkan 
dengan pentas seni budaya tradisional mulai dari Seni Bangbaraan, Pontrangan, Pencak Silat, dan yang lainnya. Nilai-nilai kearifan lokal yang terkandung di dalam Tradisi Misalin antara lain nilai religi, gotong royong, seni, sejarah, dan ekonomi. Nilai-nilai kearifan lokal tersebut relevan sepanjang masa sehingga bermanfaat bagi generasi yang mendatang.

\section{DAFTAR PUSTAKA}

Basyari, Iin Wariin. 2014. "NilaiNilai Kearifan Lokal (Local Wisdom) Tradisi Memitu Pada Masyarakat Cirebon (Studi Masyarakat Desa Setupatok Kecamatan Mundu)." Edunomic. Vol. 2. No. 1. Hlm. 48-56.

Gottschalk, Louis. 1975. Mengerti Sejarah (Terjemahan). Jakarta: Yayasan Penerbitan Universitas Indonesia.

Herlina, Nina. 2008. Metode Sejarah. Bandung: Satya Historika.

Nalurita, dkk. t.t. “Fungsi Ronggeng Ibing Dalam Upacara Ngabungbang Di Desa Batulawang Kota Banjar." Universitas Pendidikan Indonesia. Hlm. 1-13.

Nasution, Muhammad Syukri Albani, dkk. 2015. Ilmu Sosial
Budaya Dasar. Jakarta: Rajawali Pers.

Mujamil, Miming, dan Tetet Widiyanti. 2014. Kabupaten Ciamis Dalam Sudut Pandang Sejarah Dan Nilai Budaya. Ciamis: Pemerintah Kabupaten Ciamis Dinas Pendidikan dan Kebudayaan.

Peurson, C.A. Van. 1988. Strategi Kebudayaan. Yogyakarta: Kanisius.

Sjamsuddin, Helius. 2007. Metodologi Sejarah. Yogyakarta: Ombak.

Sugono, Dendy (pemred). 2008. Tesaurus Bahasa Indonesia. Jakarta: Depdiknas

Wikantiyoso, Respati, dan Pindo Tutuko. 2009. Kearifan Lokal Dalam Perencanaan Dan Perancangan Kota; Untuk Mewujudkan Arsitektur Kota Yang Berkelanjutan. Malang: Group Konservasi Arsitektur \& Kota.

Yunus, Rasid. 2014. Nilai-Nilai Kearifan Lokal (Local Genius) Sebagai Penguat Karakter Bangsa (Studi Empiris Tentang Huyula. Yogyakarta: Deepublish. 